\title{
Epithelioid Hemangioendothelioma- Two Rare Case Reports with Review of Literature
}

\author{
J. Logeswari ${ }^{1}$, B. Sabarinath ${ }^{1}$, B. Sivapathasundharam ${ }^{2}$ \\ ${ }^{1}$ Associate Professor, ${ }^{2}$ Professor and Head, Department of Oral Pathology, Meenakshi Academy of Higher \\ Education and Research, Faculty of Dentistry, Meenakshi Ammal Dental College, Maduravoyal,
}

Chennai-600095, India

\begin{abstract}
Epithelioid hemangioendotheliomas (EHE) are decidedly are form of hemangioendotheliomas with biphasic histopathological components. It is known to occur rarely in head and neck region. They are known to have aggressive behaviour with depictable recurrence rate and metastasis. Here we present two cases of epithelioidhemangioendothelioma with review of literature.
\end{abstract}

Keywords: Hemangioendothelioma, Epithelioid, Vascular Neoplasms, Metastasis, immunoreactivity.

\section{Introduction}

Hemangioendotheliomas (HE) are rare proliferative vascular neoplasms, known for its intermediate biological behavior that ranges between benign hemangiomas to malignant angiosarcomas. ${ }^{[1-6]}$ Its clinical behavior and disease course remains unpredictable even amongst its histological types namely epithelioid, kaposi's and hobnail form (Dabska-retiform). Epithelioidhemangioendotheliomas (EHE) are decidedly are form of hemangioendotheliomas with biphasic histopathological components composed of characteristic short cords and nests of proliferating round to epithelioid endothelial cells as well as spindle shaped endothelial cells. It is known to occur in any soft tissues but primarily in abdomen, liver, lung, extremities and also rarely in head and neck region..$^{2-6}$ Epithelioidhemangioendotheliomas are known to have

\section{Corresponding Author:}

\section{J. Logeswari}

Associate Professor, Department of Oral Pathology, Meenakshi Academy of Higher Education and Research, Faculty of Dentistry, Meenakshi Ammal Dental College, Maduravoyal, Chennai - 600 095, India.

e-mail: drlogi.oralpathology@madch.edu.in aggressive behavior with exemplified recurrence rate and metastasis, than any other types. ${ }^{[7-9]}$

The exact nature of intra oral EHE is not clearly established because of its rarity. Till now only thirty four cases of intra oral EHE cases have been reported in English literature, including current two cases.

Case 1: A 35 year old female patient reported to the dental clinic with a chief complaint of red to pink, painless swelling in right lateral border of the anterior tongue (Fig. 1). The swelling was present for past three months which increased gradually to the present size of $3 \times 1 \mathrm{~cm}^{2}$. It is a lobulated, ovoid mass with a sessile base. The clinical differential diagnosis of hemangioma, fibroma, and pyogenic granuloma, was considered based on the clinical appearance and incision was performed after routine investigations.

The microscopic examination revealed plenty of tiny blood vessels lined by round to oval and spindled epithelioid cells, exhibiting eosinophilic cytoplasm with vacuolization arranged in short cords and nest (Fig. 2). Mitotic figures were minimal in number. The overlying epithelium was stretched and hyperplastic with surface ulcerations. Based on this diagnosis of EHE was considered. The tumour cells also exhibited immunoreactivity for CD31 confirming the endothelial nature of epithelioid cells and negative expression for cytokeratin and thus EHE was confirmed. 
Chest radiograph was taken to rule out metastasis. Complete excision of the lesion was done. Patient reported after three months with no recurrence and complications and failed to report back further.

Case 2: A 22 year old male patient reported to a dental office with a complaint of solitary painful, mass in the buccal mucosa for past six months. The swelling was red to grey in colour with surface ulceration in the center of the mass. The swelling developed gradually to the present size of $3 \times 2 \mathrm{~cm}^{2}$. Patient gives frequent history of trauma on mastication otherwise no other symptoms were elucidated in relation to the growth. Family and personal history was unremarkable.

Provisional diagnosis of traumatic fibroma was given. Incision biopsy was performed and tumour mass was submitted for histopathological analysis. Tumour was yellow to grey solid mass with soft to firm consistency. The microscopic examination revealed cords and nests of proliferating spindle cells along with round to oval epithelioid cells with eosinophilic cytoplasm and intracellular vacuolization indispersed within a loose fibrovascular connective tissue stroma with plenty of tiny blood vessels. Few mitotic figures were evident. Overlying peripheral epithelial lining was also evident. Positive immunoreactivity of tumour cells for CD31 confirming the endothelial nature of epithelioid cells and negative expression of cytokeratin was elucidated. Considering the histopathological and immunohistochemical features, diagnosis of EHE was made.

Surgical excision of the tumour was performed and the patient was disease free till follow up examination of 16 months.

\section{Discussion}

Hemangioendothelioma is rare proliferative vascular neoplasm with intermediate malignant potential. ${ }^{[3,9]}$ The variable behavior of the neoplasm, led to its compounded terminologies such as histiocytoidhemangioma, intravascular bronchioalveol ar,malignanthemangioendothelioma, cellular angioma of infancy, angioendothelioma, angioblastoma and led to the categorization of $\mathrm{HE}$ as an intermediate tumors or borderline tumor. ${ }^{[1,2,4,6,10-12]}$ Though the concept of intermediate or borderline tumours remains complex and ill defined, it was designated to tumours with uncertain behavior. It was described as early as 1899 by Boremann, ${ }^{[4,5,8]}$ and was introduced particularly in vascular tumours by Enzinger and Weiss and latter added to WHO classification in $2002 .{ }^{[3,4,6,9]}$ These HE lack consistent clinical and histological behavior with limited number of reported cases, fails to elucidate the exact biological nature of this tumour.

The first case of oral HE occurring at gingival was reported at 1975 by Wisely et al, as "primary malignant hemangioendothelioma". Later in 1986 Ellis and Kratochvil reported twelve cases. The three histological variables listed under HE are epithelioid, kapossis and hobnail (dabska-retiform). Amongst is histological type, EHE are relatively rare, aggressive member of this group with unpredictable behavior with increased tendency for recurrence and metastases.

The term EHE was first described and reviewed by Weiss and Enzinger in 1982. They are known to occur in diverse locations, including abdomen, liver, spleen, kidney, extremities, head and neck regions and rarely in bones. Lesions occurring in different anatomical location do not follow a synonymous biological behavior. The incidence of EHE occurring in oral cavity, are decidedly rare, where only 34 cases have been reported till date (inclusive of current two cases).

The common intra oral sites include gingiva, tongue, palatal mucosa, floor of the mouth and rarely alveolar bone with gingival (38.2\%) and tongue (29.4\%) being the most frequent site. ${ }^{[4,5,8,10,13,14,15]}$. The lesion is present at the tongue, the most frequent site while the second one reported at the less frequent site, the buccal mucosa.

A wide range of age group is being affected ranging from first to seventh decade of life with mean age of 34.7 years. Men and women are equally affected except few authors believe slight female predilection in those occurring in extremities. No predisposing factors have been claimed for its occurrence except contraceptives usage in females as mentioned by few authors ${ }^{[10,11,16]}$.

Clinically, lesion appears as a solitary, painful to painless red to grey soft tissue mass with size not greater than $2 \mathrm{~cm}$ hinting for benign nature and confuses with more common lesions such as pyogenic granuloma, fibroma, fibroepithelial polyp, peripheral giant cell granuloma and hemangiomas. ${ }^{[1,11]}$ Radiographic details are usually non contributory, showing a mild bone resorption. Normally excision is performed considering other common benign lesions as provisional diagnosis. 
Histologically, these lesions are characterized by proliferating sheets, cords and islands of eosinophilic round to oval shaped epithelioid cells intermixed with strands of spindle shaped cells around proliferating tiny blood capillaries (Figure 3\&4). The morphology of cells is epithelioid in shape, with round to oval nucleus with occasional intracytoplasmic-lumina. The classic intracytoplasmic-lumina(vacuolization) with round to oval vesicular nucleus are the distinct feature of EHE (Figure 5). The lumen is frequently filled with RBCs may account for a primitive vessel formation and also suggests the endothelial origin. Frequently collagenous and myxohyaline areas are reported in tumor stroma ${ }^{[4-6]}$, which was evident in the second case. Few authors attest it could possibly be a sulfated acid mucin from vessel wall ${ }^{[2]}$ and also specifies the endothelial nature of the lesion. Infrequently few areas of calcifications, multinucleated giant cells and mitotic figures are also reported $[3,4,6,9]$. Angiocentricity is not very well appreciated in oral lesions in contrast to cutaneous lesions, where only less than $9 \%$ of oral lesions showed history of pain, ischemia could be the probable reason for pain ${ }^{[1,6]}$. Advent of cytology in diagnosis of EHE occurring in other extra oral sites were found useful, and showed $85 \%$ positivity in reported cases. However its usage in oral lesions as an adjuvant, not yet described.

Immunohistochemistry plays a confirmatory role in rendering diagnosis as well as differentiating it from other histologically similar lesions [4,6,7,9,13]. Look alike lesions includes epithelioid sarcomas, other metastatic carcinomas and vascular lesions like epithelioidhemangiomas, epithelioidangiosarcoma and epithelioid spindle cell hemangioma. Endothelial markers such as CD 31, CD 34, CD 68, Factor VIII were used in previously reported cases to aid in diagnosis of the vascular nature of lesion. While the epithelial markers like cytokeratin, epithelial membrane antigen are frequently found negative and excludes the epithelial origin ${ }^{[1,5,10,17]}$. It permits us to presume that, these epithelioid cells are altered endothelial cells rather true epithelioid cells. Few case reports with focal cytokeratin positive immumoreactivity ${ }^{[1,10,14]}$ also complicates the diagnosis, however the knowledge of the pathologist along with the adjuvants contributes in differentiating further. The positive immunostaining for CD 31 cytokeratin and negative staining (Figure 6\&7) confirmed the diagnosis assisted in removing other differential diagnosis including epithelioid sarcomas and other metastatic carcinomas which are frequent and indigenous to the tissue of origin.

Local recurrence is not uncommon in EHE but intra oral cases accounts relatively lesser frequency, compared to those occurring in other anatomical site. Out of 34 cases, collective sum of earlier reviews and the current review, affirms the raise in propensity of recurrence at the rate of $22.5 \%$ in intra oral cases, specially with gingival cases ${ }^{[7,19]}$, It is not unknown for EHE to metastasis, especially to the regional lymph nodes, at the however distant metastasis is seldom noticed. Despite features like cellular pleomorphism, altered nuclear cytoplasmic ratio, increased number of mitotic figures (more than 3mitosis/50HPF) [6,7,18,19], metaplastic bone formation, areas of necrosis and few authors prefer including the tumour size greater than $3 \mathrm{~cm}$ diameter, can be considered for predicting the recurrence and metastasis. It requires more clarity, to claim it as a criterion, since much times, lesion also develop metastasis and recurrences from an indolent lesion with bland histopathology. Multicentiricity of EHE is a well appreciated, frequent event in extremities and found have better prognosis than the unifocal ones, whereas, it is exceptionally rare in oral cavity.

Wide excision is a preferred treatment of choice, reflecting the intermediate malignant potential of the tumour but recurrence is commonly associated with inadequate excision. On other hand adjuvant therapies such as radiotherapy and chemotherapy are frequently suggested, for recurrent cases, merely found effective. Mortality rate in relation to oral EHE is not recorded till date that assents us to consider oral lesions are relatively less aggressive compared to those occurring in other areas of body.

Thus oral EHEs are rare intermediate vascular neoplasms, with increased tendency for recurrence and metastasis appears frequently as a sessile benign lesion. Considering the raise in recurrence rate especially with those occurring in gingiva, all lesion with high vascularity should be considered as a common differential diagnosis. Those diagnosed with EHE, should be evaluated for, recurrence and metastasis with long term follow up. In both the cases did not present any atypical features microscopically, chest radiograph were also evaluated, in order to exclude the possibility of metastasis and also insisted on frequent followup to rule out recurrence. 
Acknowledgement: Dr. V. Vasanthakumar, Department of Faciomaxillary and Dental Surgery, Government Vellore Medical college and Hospital, Vellore, Tamil Nadu, India

\section{Financial Support: Nil}

Conflicts of Interest: There are no conflicts of interest

\section{Ethical Clearance: Nil}

\section{References}

1. Naqvi J, Ordonez NG, Luna MA, Williams MD, Weber RS, El-Naggar AK. Epithelioid hemangioendothelioma of the head and neck: role of podoplanin in the differential diagnosis. Head and neck pathology. 2008 Mar 1;2(1):25-30..

2. Mohtasham N, Kharrazi AA, Jamshidi S, Jafarzadeh H. Epithelioid hemangioendothelioma of the oral cavity: a case report. Journal of oral science. 2008;50(2):219-23..

3. Yuca K, Kösem M, Yuca SA, Oral H, Bay A. Report of a girl with infantile hemangioendothelioma. 2005;2(2):80-82.

4. Uehara M, Shibahara K, Fujita S, Tobita T, Ohba S, Fujisawa A, Nonaka M, Inokuchi T. Epithelioid hemangioendothelioma of tongue: A case report with immunohistochemical studies. Oral Oncology Extra. 2006 Mar 1;42(3):101-4..

5. Weiss SW, Enzinger FM. Epithelioid hemangioendothelioma a vascular tumor often mistaken for a carcinoma. Cancer. 1982 Sep 1;50(5):970-81.

6. Sawair FA, Cheng J, Yamazaki M, Al-Eryani K, Khraisat A, Ono Y, Kito K, Ono K, Takagi R, Saku T. Epithelioid hemangioendothelioma of the tongue: a report of solitary and multiple lesions in two young children. Oral Medicine \& Pathology. 2008;13(1):15-20..

7. Gordón-Núñez MA, Lopes MF, Maia AP, Galvão HC. Intraoral epithelioid hemangioendothelioma: a case report and review of the literature. Medicina oral, patologia oral y cirugia bucal. 2010 Mar;15(2):e340-6.

8. Gherman CD, Fodor D. Epithelioid hemangioendothelioma of the forearm with radius involvement. Case report. Diagnostic pathology. $2011 \mathrm{Dec} ; 6(1): 1-5$.
9. Machálka M, Procházková L, Hušek K. Epithelioid hemangioendothelioma of the mandible. Mund, Kiefer-und Gesichtschirurgie. 2003 May 1;7(3): 180-3.

10. Marrogi AJ, Boyd D, El-Mofty SK, Waldron C. Epithelioid hemangioendothelioma of the oral cavity: report of two cases and review of literature. Journal of oral and maxillofacial surgery. 1991 Jun 1;49(6):633-8.

11. Orsini G, fioroni M, rubini C, Piaptelli A Epithelioid Hemanngioendothelioma of the oral cavity: Report of case journal of oral maxilliofacialsurgry 2001,59:334-337

12. Gould RA intra oral epitheliodhemangioendothelioma report of two cases and review of literature. Journal of oral maxillofacial surgery oral medicine endodontics 20005;100(2)186

13. Sun ZJ, Zhank, Zhank WF, Chen XM, Lai FMM, Zhao YF. Epithelioid Hemanngioendothelioma of the oral cavity.oral diseases 2007 13;244-249

14. Aksoy EA, Atalar B, Beylergil V, Unal OF uresitectable Epithelioid Hemanngioendothelioma of the neck region cured by radiotherapy, journal of medical cases 2011; 2(4):147-150

15. Liu Q,Miao J, LianK, Huang L,DiangZ. Multicentric EpithelioidHemanngioendothelioma involving the same lower extrimeties case report in review of literature. International journal of medical scienses 2011;8(7):558-563

16. Manjunatha B, Kumar GS, Vandana R, Intra oral Epithelioid Hemangioendothelioma:an intermediate vascular Tumor-A case report. Dental Research journal 2009;6(2):99-102

17. Murali R, Zarka MA, Ocal.IT, Tazelaar. HD. cytologic features of Epitheloid Hemangioendothelioma Americal Society for Clinical pathology, 2011;136:739-746.

18. Buch.Ac, Chandanwale SS, Sood Sk, Bamanikar. SA. Epithelioidhemangioendothelioma: A rare vascular tumour, clinical Investigation journal 2013;263-265

19. Albuquerque AK, Romano SD, Eisenberg AL. Epithelioid hemangioendothelioma: 15 years at the National Cancer Institute. Literature review. Jornal Brasileiro de Patologia e Medicina Laboratorial. 2013 Apr;49(2):119-25.. 
20. Cheng YS, Kessler H, Rees TD, Philofsky D, Pontikas A. Gingival swelling in a 13-year-old girl with multiple recurrences. Oral Surgery, Oral Medicine, Oral Pathology, Oral Radiology, and Endodontology. 2007 Jan 1;103(1):85-91.
21. Mohtasham N, Kharrazi AA, Jamshidi S, Jafarzadeh H. Epithelioid hemangioendothelioma of the oral cavity: a case report. Journal of oral science. 2008;50(2):219-23. 